\title{
Subcapsular hepatic hematoma as a complication of severe preeclampsia: a case report
}

\author{
Kiel Luhning, Hilary MacCormick, Bruce Macaulay, Marianna Saunders and Catherine Craig ${ }^{*}$
}

\begin{abstract}
Background: Subcapsular hepatic hematoma is a rare and life-threatening complication of pregnancy. It is most commonly associated with severe preeclampsia and hemolytic anemia, elevated liver enzymes, and low platelets syndrome. Patients with subcapsular hepatic hematoma typically present with epigastric, right upper quadrant or shoulder pain, nausea and vomiting, and/or shortness of breath. Here we describe a patient with a classic pain presentation, a large unruptured hematoma, and an unusual postpartum course.

Case: A 40-year-old gravida 1 para 0 Caucasian woman presented at $39+6$ weeks gestational age with a 3-day history of new onset pain in an otherwise uncomplicated pregnancy. She described the pain along her right torso as severe, shooting, and sharp, but at times pleuritic in nature. She was found to have new onset preeclampsia and hemolytic anemia, elevated liver enzymes, and low platelets syndrome. Induction of labor was initiated and eventually she delivered by cesarean section. Her pain persisted in the postpartum period and abdominal computed tomography scan revealed a $16 \mathrm{~cm}$ subcapsular hepatic hematoma. Despite the hematoma being thin walled, conservative management was recommended by the general surgeon. She then re-presented on postpartum day 15 with tachypnea, dyspnea, and pleuritic chest pain. Secondary to the subcapsular hepatic hematoma, she then developed an infected and loculated, large pleural effusion. This required video-assisted thoracoscopic surgery before her eventual discharge home on postpartum day 21.

Conclusions: There should be high clinical suspicion of subcapsular hepatic hematoma in patients with persistent pain in the right upper quadrant of the abdomen. Urgent imaging to investigate for subcapsular hepatic hematoma is then indicated. Cesarean delivery without labor and treatment for severe preeclampsia should be undertaken if subcapsular hepatic hematoma is found. Conservative management and serial imaging are reasonable for the followup of a large, unruptured hematoma. Hepatic artery embolization should also be considered. Subcapsular hepatic hematoma may be complicated by infected pleural effusions and require video-assisted thoracoscopic surgery.
\end{abstract}

Keywords: Severe preeclampsia, Subcapsular (liver) hematoma, Unruptured hematoma, Infected pleural effusion, Video-assisted thoracoscopic surgery

\section{Background}

Subcapsular hepatic hematoma $(\mathrm{SCH})$ is a rare and lifethreatening complication of pregnancy [1]. The pathogenesis of $\mathrm{SCH}$ is not well understood. The common

*Correspondence: catherine.craig8@gmail.com

Dalhousie University, Halifax, NS, Canada proposed mechanism includes endothelial injury secondary to preeclampsia, fibrin deposition, hepatic sinusoidal obstruction, neovascularization, and microhemorrhage leading to hematoma formation [2-5]. Rarely, $\mathrm{SCH}$ are reported with coexisting pleural effusion or renal hematoma [3]. SCH is most commonly associated with severe preeclampsia and hemolytic anemia, elevated original author(s) and the source, provide a link to the Creative Commons licence, and indicate if changes were made. The images or other third party material in this article are included in the article's Creative Commons licence, unless indicated otherwise in a credit line to the material. If material is not included in the article's Creative Commons licence and your intended use is not permitted by statutory regulation or exceeds the permitted use, you will need to obtain permission directly from the copyright holder. To view a copy of this licence, visit http://creativecommons.org/licenses/by/4.0/. The Creative Commons Public Domain Dedication waiver (http://creativeco mmons.org/publicdomain/zero/1.0/) applies to the data made available in this article, unless otherwise stated in a credit line to the data. 
liver enzymes, and low platelets (HELLP) syndrome [1]. However, the differential diagnosis includes hepatic neoplasms, infectious processes, aneurysms, and biliary disease [6]. Although preeclampsia occurs more commonly in young primigravida, $\mathrm{SCH}$ seems to be more common in multiparous patients with advanced maternal age [5]. Unfortunately, there is no correlation between laboratory abnormalities and presence of $\mathrm{SCH}$ [2]. However, the diagnosis of $\mathrm{SCH}$ must be considered in patients with stereotypical pain presentation, including severe shoulder, back, or epigastric pain, particularly if the pain does not respond to conservative treatments, including acetaminophen, opioids, and epidural analgesia $[2,3,6$, 7]. Here we describe a patient with a classic pain presentation, a large unruptured hematoma, and an unusual postpartum course.

\section{Case}

A 40-year-old gravida 1 para 0 Caucasian woman presented at $39+6$ weeks gestational age with a 3-day history of new onset pain in an otherwise uncomplicated pregnancy. At $39+1$ weeks gestation she had started outpatient cervical ripening with dinoprostone (Cervidil) because of her advanced maternal age. She described the pain along her right torso as severe, shooting, and sharp, but at times pleuritic in nature. It rapidly progressed from her right trapezius to encompass the entirety of her right torso, from her upper abdominal quadrant and epigastrium, radiating to her back, chest, shoulder, and neck. Her pain was initially attributed to possible radiculopathy, as she had a previous history of the same. Her vital signs at initial presentation were normal, with no hypertension noted, and there were no concerns regarding the fetal status. No further investigations were ordered and a full neurological examination was not documented.

She represented less than 24 hours later at $40+0$ weeks gestational age, and was found to be hypertensive at $157 / 101$ and $164 / 112 \mathrm{mmHg}$. Oxygen saturation was $98 \%$ on room air. She had sinus tachycardia on arrival, ranging from 110 to $140 \mathrm{bpm}$ and persisting throughout the peripartum period. She was tender in the right upper quadrant, however there were no peritoneal signs, and no hepatomegaly was appreciated in the presence of the gravid uterus. She was tender from the right side of her neck through to her right lower back. Her reflexes were $3+$ bilaterally with no clonus. The fetal heart rate was normal. Her blood investigations revealed a hemoglobin of $105 \mathrm{~g} / \mathrm{L}$, platelets $156,000 \mathrm{~g} / \mathrm{L}$, alanine aminotransferase (ALT) $193 \mu / \mathrm{L}$, aspartate aminotransferase (AST) $111 \mu / \mathrm{L}$, and uric acid $429 \mu \mathrm{mol} / \mathrm{L}$. White blood cell count, creatinine, lactate dehydrogenase (LDH), and coagulation profile were within the normal range. An electrocardiogram (ECG) showed sinus rhythm with no abnormal features, apart from the previously noted tachycardia.

After diagnosing preeclampsia, induction of labor was started, as was an infusion of magnesium sulfate. Due to the unusual but significant pain that she was experiencing, a range of differential diagnoses were considered by the obstetrical and anesthesia team. Preeclampsia with HELLP syndrome was the working diagnosis, however differential diagnoses included fatty liver, radiculopathy, cholecystitis, pancreatitis, and pyelonephritis. The patient requested labor analgesia be initiated and a combined spinal epidural was placed when the patient's cervix was $2 \mathrm{~cm}$ dilated. Analgesia was maintained via programmed intermittent epidural bolus with patientcontrolled epidural analgesia as needed, in keeping with our institutional practice. The patient reported satisfactory analgesia with regard to her labor pain, but still complained of severe pain in her right torso that was unresponsive to acetaminophen and opioids. Blood investigations monitored every 4 hours remained stable with hemoglobin of 103-102 g/L, platelets 158,000$165,000 \mathrm{~g} / \mathrm{L}$, ALT $176-169 \mu / \mathrm{L}$, AST $100-97 \mu / \mathrm{L}$, and uric acid $400-420 \mu \mathrm{mol} / \mathrm{L}$. The $\mathrm{LDH}$, creatinine, and coagulation profile remained normal. Labor progressed to full dilation with oxytocin augmentation, but as a result of torso pain she was unable to exert adequate effort with pushing. Ultimately, the obstetrical team consented the patient for a trial of forceps and possible cesarean delivery.

In the operating room, the obstetrics team performed an examination under anesthesia, which revealed the fetus to be in an occiput-transverse position at station zero, and the decision was made to proceed to cesarean delivery as the station was too high to perform a trial of forceps. A nonvigorous male infant was delivered with Apgar scores of 3 and 8 at 1 and 5 minutes, respectively. Placental delivery was uneventful. Atonic postpartum hemorrhage was treated with a bolus of 2 units IV oxytocin and carboprost $250 \mathrm{mcg}$ intramuscular (IM), in addition to an oxytocin infusion. As per our institutional practice, a bolus of oxytocin is only used when the patient has multiple risk factors for intraoperative hemorrhage or is experiencing uterine atony. This low dose was chosen to prevent potential side effects (nausea, vomiting, chest pain) and complications (hypotension, hypertension, ST segment changes, myocardial ischemia, bronchospasm) that can be associated with higher dose boluses when given at the time of cesarean section [8, 9]. Prior to fascial closure, the obstetrics team manually explored the abdomen to the extent possible through the Pfannenstiel incision. No gross abnormalities were identified. The patient's right torso pain persisted throughout her time in the operating room, with only a slight 
improvement after surgical anesthesia obtained via the epidural. After delivery, $2.5 \mathrm{mg}$ of epidural morphine was given for postoperative analgesia. The patient was hemodynamically stable throughout the operation, although remained tachycardic. Estimated blood loss was approximately $900 \mathrm{~mL}$. Postoperatively, the patient was sent for a computed tomography (CT) scan of her chest, abdomen, and pelvis, including contrast for a pulmonary embolism protocol to investigate the abdominal pain and persistent tachycardia. No pulmonary embolus was found and a small right pleural effusion with subsegmental atelectasis was noted. However, the most impressive feature on the scan was a large but intact subcapsular liver hematoma that measured approximately $16 \times 7 \times 14 \mathrm{~cm}$ (Fig. 1 ). Portal hypertension was suggested by the presence of portosystemic varices. The general surgery team was consulted and recommended conservative management with strict blood pressure control requiring oral labetalol, frequent complete blood count $(\mathrm{CBC})$ monitoring, and 48 hours of bedrest. If, however, the $\mathrm{SCH}$ had been diagnosed antepartum, labor would have been avoided and delivery would have been expedited via immediate cesarean section. The $\mathrm{SCH}$ is at risk of rupture with active pushing, convulsions, or abdominal trauma, including vigorous palpation of the right upper quadrant [2]. In this case, prophylactic antibiotics were not used as there were no signs of infection and the underlying etiology was noninfectious. Interventional radiology was on standby

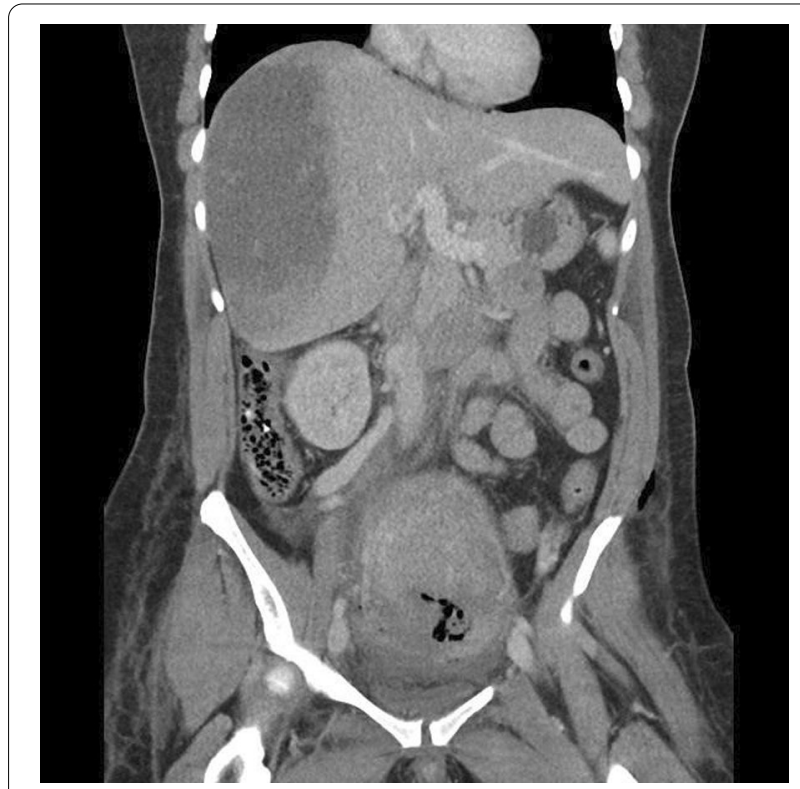

Fig. 1 1. Initial CT abdomen: Large subcapsular liver hematoma measuring $16 \mathrm{~cm}$ in maximum cranial-caudal dimension. Heterogeneous attenuation is compatible with blood product of varying ages. No active bleed was identified. There is significant mass effect on the liver, however the liver parenchyma was normal. to perform hepatic artery embolization if the $\mathrm{SCH}$ significantly increased in size or there was concern about imminent rupture. Serial monitoring of blood work revealed a hemoglobin of $70 \mathrm{~g} / \mathrm{L}$ and $56 \mathrm{~g} / \mathrm{L}$ on postoperative days 1 and 2, respectively, prompting transfusion of two units of packed red blood cells on day 2. The patient was discharged on postoperative day 5 with her hemoglobin stable at $85 \mathrm{~g} / \mathrm{L}$.

An early postoperative follow-up visit was arranged 15 days postpartum and at that visit the patient was noted to be pale, tachypneic, and upon questioning she stated increasing shortness of breath and a persistence of her pleuritic chest pain. She was sent back to the IWK Health Centre where her vital signs were as follows: heart rate $110-130 \mathrm{bpm}$, blood pressure $112 / 66 \mathrm{mmHg}$, oxygen saturation $97 \%$ on room air, respiratory rate $40-48$, temperature $37.9{ }^{\circ} \mathrm{C}$. Blood investigations revealed a white cell count of 6, hemoglobin $97 \mathrm{~g} / \mathrm{L}$, platelets $650,000 \mathrm{~g} / \mathrm{L}$, ALT $75 \mu / \mathrm{L}$, AST $88 \mu / \mathrm{L}$, LDH $1310 \mu / \mathrm{L}$, and coagulation profile remained normal. A repeat abdominal CT scan reported an increase in the size of the liver hematoma to $14 \times 8.5 \times 18.3 \mathrm{~cm}$ (Fig. 2). Although there was no evidence of active intralesional bleeding or rupture, the liver capsule was difficult to visualize in the superior aspect,

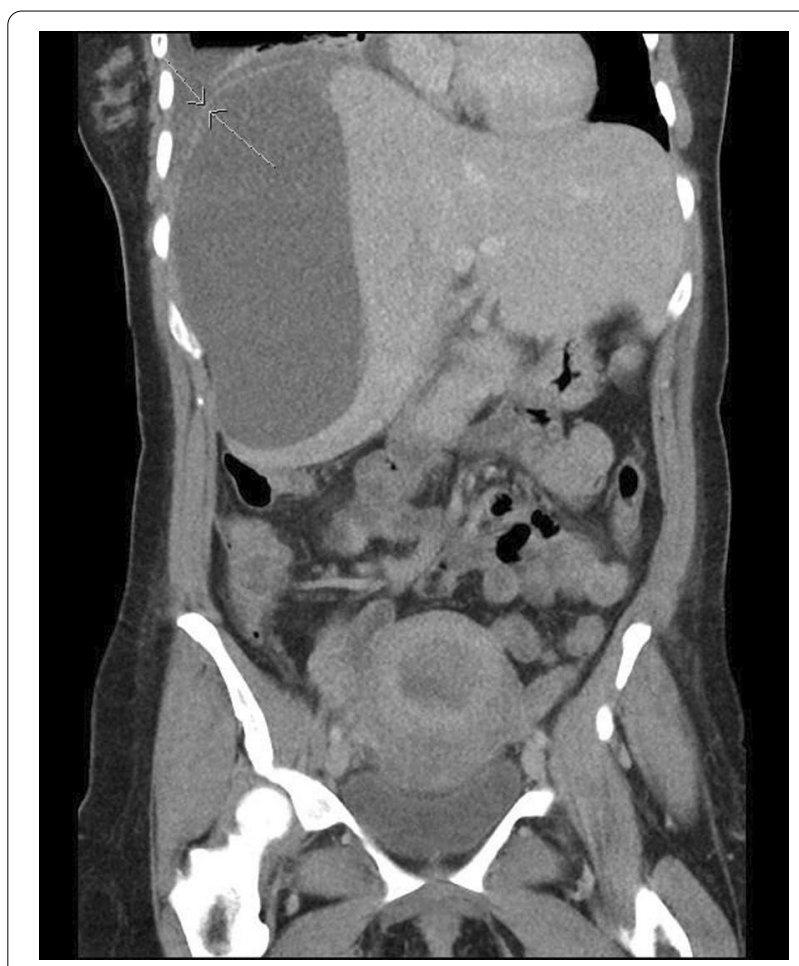

Fig. 2 Computed tomography abdomen postoperative day 15: Large subcapsular liver hematoma has increased in size, now measuring $18 \mathrm{~cm}$ in cranial-caudal dimension. However, no CT features of active bleed are present. Along the superior margin of the hematoma, the liver capsule demonstrates marked thinning. 
and could suggest significant thinning and imminent rupture. The CT scan of the chest reported a large right pleural effusion with mediastinal shift (Fig. 3).

The patient was urgently transferred from the standalone maternity hospital to a nearby hospital under the care of the thoracic surgery team, with the general surgery team on standby. A chest tube was placed, but ultimately the patient required video-assisted thoracoscopic surgery (VATS), with right partial decortication of an infected, loculated pleural effusion prior to her discharge home. The pleural effusion aspirate showed no growth. The right pleural effusion was felt to be exudative in nature and secondary to the adjacent large $\mathrm{SCH}$. Throughout the admission she remained normotensive and her hepatic hematoma remained stable with no signs of active bleeding. She was discharged home on day 2 following the VATS procedure, coinciding with day 21 following her cesarean section. At discharge, her hemoglobin was $74 \mathrm{~g} / \mathrm{L}$ and her platelets were $884,000 \mathrm{~g} / \mathrm{L}$.

She continued to receive follow-up with general surgery and obstetrics as an outpatient. A CT performed 4 weeks postpartum showed the hepatic hematoma had decreased in size to $12.6 \times 6.4 \times 15.1 \mathrm{~cm}$ and at 6 months postpartum had decreased to $3.8 \times 2.2 \times 3.1 \mathrm{~cm}$ and did not require any further follow-up.

\section{Conclusion}

$\mathrm{SCH}$ should be suspected in patients who present with severe preeclampsia or HELLP syndrome, particularly if the patient's right upper quadrant or epigastric pain is unrelenting and unresponsive to conventional interventions such as acetaminophen, opioids, and epidural analgesia. Timely diagnosis is critical as this can be a

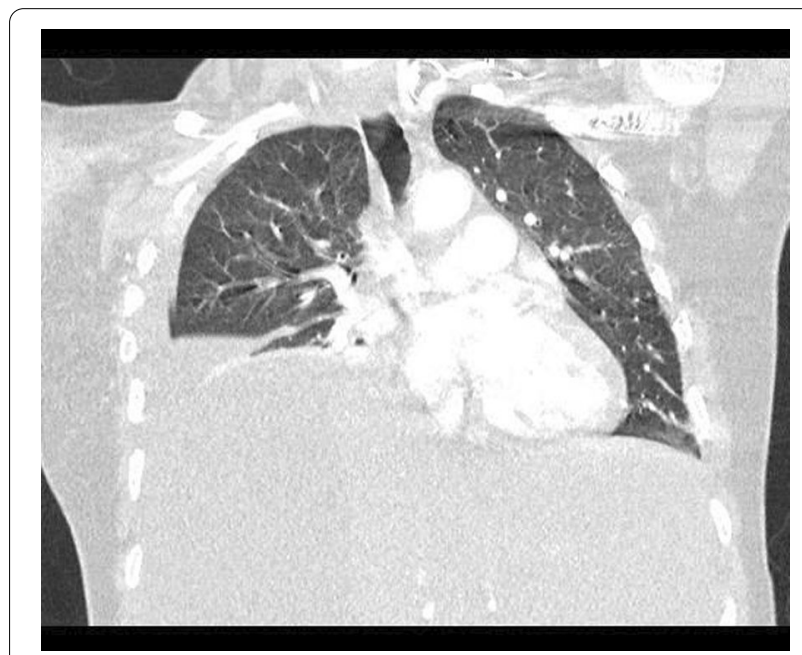

Fig. 3 Computed tomography chest postoperative day 15: Large right sided pleural effusion with mediastinal shift. life-threatening illness, especially if the $\mathrm{SCH}$ ruptures [1]. Investigation with either abdominal ultrasound, computed tomography, or magnetic resonance imaging accurately diagnoses the presence of $\mathrm{SCH}[1,3]$. If diagnosed antepartum, it is best to treat for severe preeclampsia with infusion of magnesium sulfate, blood pressure control, and expedited delivery via immediate caesarean section [6]. If $\mathrm{SCH}$ is diagnosed postpartum, conservative management is appropriate if the patient is clinically stable $[1,2,5-7,10]$. Serial imaging and strict blood pressure control are warranted. Hepatic artery embolization should also be considered if local expertise is available. One should also bear in mind that patients with $\mathrm{SCH}$ can also rarely develop large, infected pleural effusions that may require a VATS procedure, as seen in this patient.

\section{Abbreviations}

SCH: Subcapsular hepatic hematoma; HELLP: Hemolytic anemia, elevated liver enzymes, and low platelets; VATS: Video-assisted thoracoscopic surgery.

\section{Acknowledgements}

Many thanks to the multidisciplinary care team at the IWK Health Centre including the nursing staff and Departments of Obstetrics, Anesthesia, and Radiology, and the Departments of Thoracic and General Surgery at the NSHA hospitals in Halifax, NS. Most importantly, thank you to this patient for giving us permission to share her medical story.

\section{Authors' contributions}

Direct care of patient: $K L, H M, B M$, and CC. Drafting of the manuscript: $K L, H M$, and CC. Manuscript editing for journal submission: KL, HM, CC, BM, and MS. All authors read and approved the final manuscript.

\section{Funding}

This study was supported by the HB Atlee Endowment Fund through the Department of Obstetrics and Gynecology, Dalhousie University, Halifax, NS.

Availability of data and materials

Not applicable.

\section{Declarations}

Ethics approval and consent to participate Not applicable.

\section{Consent for publication}

Written informed consent was obtained from the patient for publication of this case report and any accompanying images. A copy of the written consent is available for review by the Editor-in-Chief of this journal.

\section{Competing interests}

The authors declare no competing interests.

Received: 23 April 2021 Accepted: 21 October 2021

Published online: 17 December 2021

\section{References}

1. Vigil-De Gracia P, Ortega-Paz L. Pre-eclampsia/eclampsia and hepatic rupture. Int J Gynecol Obstet. 2012;1 18(3):186-9. https://doi.org/10.1016/j. ijgo.2012.03.042. 
2. Wicke C, Pereira PL, Neeser E, Flesch I, Rodegerdts EA, Becker HD. Subcapsular liver hematoma in HELLP syndrome: evaluation of diagnostic and therapeutic options - a unicenter study. Am J Obstet Gynecol. 2004;190(1):106-12. https://doi.org/10.1016/j.ajog.2003.08.029.

3. Chan AD, Gerscovich EO. Imaging of subcapsular hepatic and renal hematomas in pregnancy complicated by preeclampsia and the HELLP syndrome. J Clin Ultrasound JCU. 1999;27(1):35-40.

4. Hasan M, Bhatt R, Kabir N, Friedman JY, Cervellione K, Thurm C. Exudative pleural effusion in A woman with ruptured subcapsular hepatic hematoma presented with hellp syndrome. Am J Respir Crit Care Med. 2014;189:1.

5. Karateke A, Silfeler D, Karateke F, Kurt R, Guler A, Kartal I. HELLP syndrome complicated by subcapsular hematoma of liver: a case report and review of the literature. Case Rep Obstet Gynecol. 2014;2014:1-3. https://doi.org/ $10.1155 / 2014 / 585672$

6. Coelho T, Braga J, Sequeira M. Hepatic hematomas in pregnancy. Acta Obstet Gynecologica Scandinavica. 2000;79(10):884-6. https://doi.org/10. 1034/j.1600-0412.2000.079010884.x.

7. Messerschmidt L, Andersen LL, Sorensen MB. Postpartum HELLP syndrome and subcapsular liver haematoma. BMJ Case Rep. 2014. https:// doi.org/10.1136/bcr-2013-202503.

8. Bollag L, Lim G, Sultan P, Habib A, Landau R, Zakowski M, Tiouririne M, Bhambhani S, Carvalho B. Society for obstetric anesthesia and perinatology: consensus statement and recommendations for enhanced recovery after cesarean. Anesth Analg. 2021;132(5):1362-77. https://doi.org/10. 1213/ANE.00000000000005257.

9. Drew T, Mrinalini B. What does basic science tell us about the use of uterotonics? Best Practice Res Clin Obstet Gynaecol. 2019;61:3-14. https://doi.org/10.1016/j.bpobgyn.2019.05.017.

10. Gupta A, Joseph SR, Jeffries B. Managing a rare complication of HELLP syndrome in Australia: spontaneous liver haematoma in pregnancy. Aust N Z J Obstet Gynaecol. 2021;61:188-94. https://doi.org/10.1111/ajo. 13318.

\section{Publisher's Note}

Springer Nature remains neutral with regard to jurisdictional claims in published maps and institutional affiliations.

Ready to submit your research? Choose BMC and benefit from:

- fast, convenient online submission

- thorough peer review by experienced researchers in your field

- rapid publication on acceptance

- support for research data, including large and complex data types

- gold Open Access which fosters wider collaboration and increased citations

- maximum visibility for your research: over $100 \mathrm{M}$ website views per year

At BMC, research is always in progress.

Learn more biomedcentral.com/submissions 